Supporting Information for

\title{
Mechanistic investigation of cPMP synthase in the molybdenum cofactor biosynthesis using an uncleavable substrate analog
}

\author{
Bradley M. Hover ${ }^{\dagger}$, Edward A. Lilla ${ }^{\dagger}$ and Kenichi Yokoyama ${ }^{\dagger *}$
}

${ }^{\dagger}$ Department of Biochemistry, Duke University Medical Center, Durham, NC, 27710.

*Corresponding Author: ken.yoko@duke.edu, 


\section{Table of Contents}

\section{Supplementary Figures}

Figure S1. LCMS characterization of $3^{\prime}, 8-\mathrm{CH}_{2} \mathrm{GMP}\left[\mathrm{CH}_{2}\right] \mathrm{PP}$.

Figure S2. Chemical characterization of $[\alpha, \beta$-methyleno]intermediate $\mathrm{X}$.

Figure S3. LCMS characterization of a stable derivative of the small molecule released from the wt-MoaC·3',8$\mathrm{cH}_{2} \mathrm{GMP}\left[\mathrm{CH}_{2}\right] \mathrm{PP}$ assay.

Figure S4. Possible mechanism of non-enzymatic conversion of 9 into 6-carboxypterin. 
A. LC-MS UV Chromatography

(Absorption at $254 \mathrm{~nm}$ )

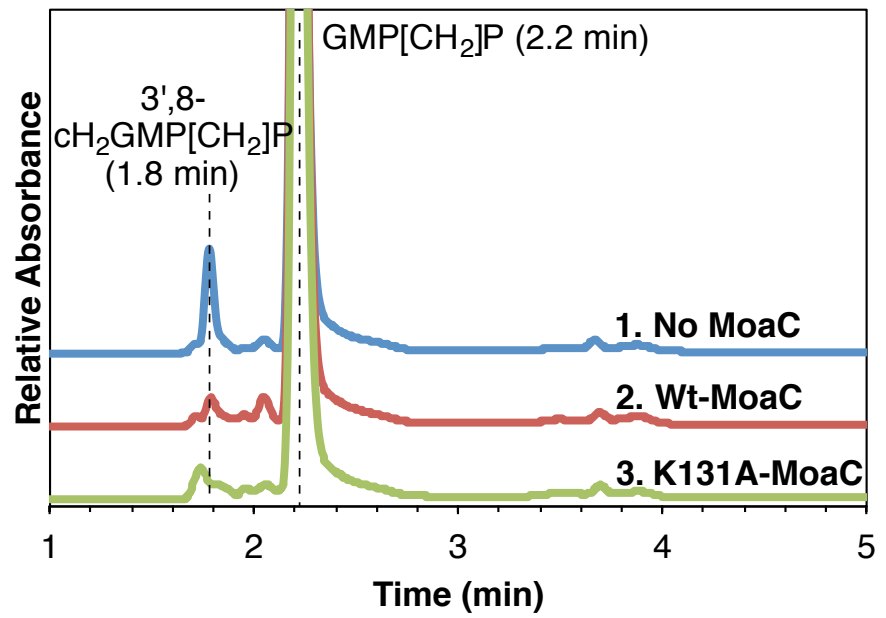

C. LC-MS Extracted Ion Chromatography

$(\mathrm{m} / \mathrm{z}=442.0523 \pm 0.050)$

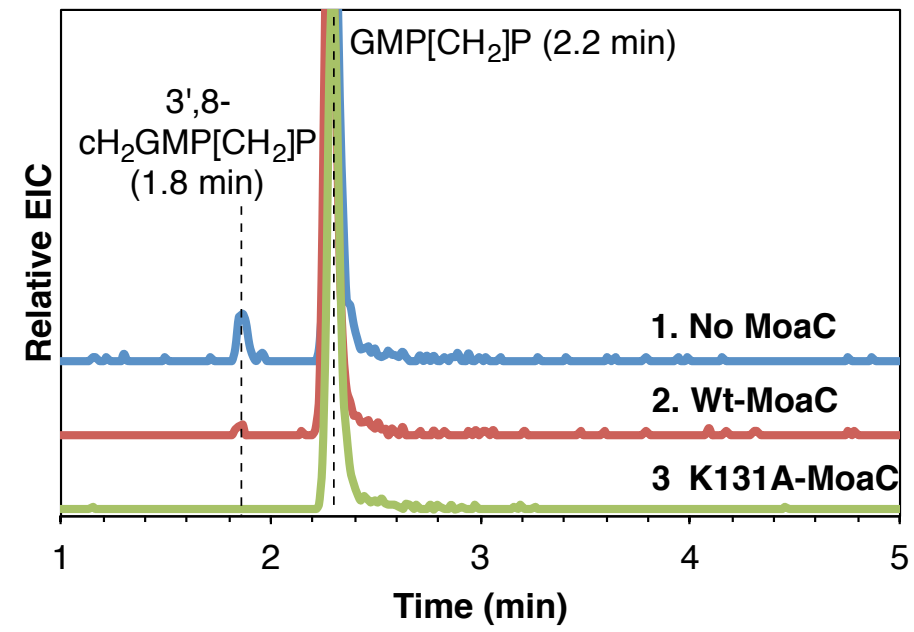

B. LC-MS UV Chromatography

(Absorption at $330 \mathrm{~nm}$ )

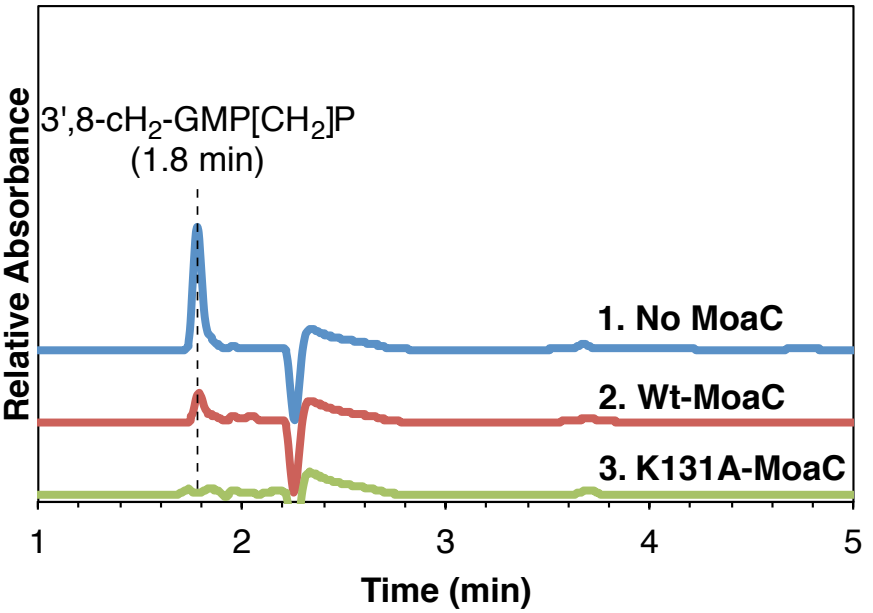

D. ESI-TOF Mass Spectra at RT $=1.8 \mathrm{~min}$

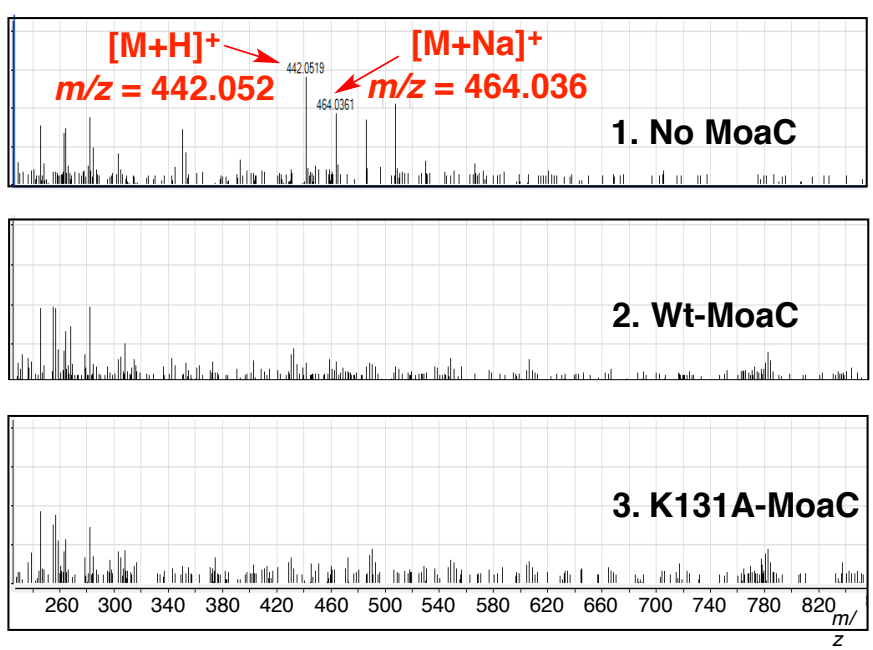

Figure S1. LCMS Characterization of $3^{\prime}, 8-\mathrm{CH}_{2} \mathrm{GMP}\left[\mathrm{CH}_{2}\right] \mathrm{PP}$. All analyses were performed anaerobically under Ar atmosphere on Agilent 6224 LC-ESI-TOF MS instrument equipped with an Agilent Poroshell $120 \mathrm{C} 18$ column $(2.1 \times 75 \mathrm{~mm}, 2.7 \mu \mathrm{m}$, Part No \#697775-906). Prior to the analysis, all samples were treated with calf intestine phosphatase (CIP) for analysis of dephosphorylated molecules $\left(\mathrm{GMP}\left[\mathrm{CH}_{2}\right] \mathrm{P}\right.$, guanosine $[(\alpha, \beta)$ methyleno]diphosphate; and $\left.\quad 3^{\prime}, 8-\mathrm{CH}_{2} \mathrm{GMP}_{\mathrm{CH}}\right] \mathrm{P}, \quad 3^{\prime}, 8$-cyclic-7,8-dihydroguanosine $\quad[(a, \beta)$ methyleno]diphosphate), which allowed separation on the $\mathrm{C} 18$ column, and sensitive detection by the positive ion detection mode. (A,B,C) Liquid chromatography of products of MoaA assay with GMP[CH $\left.\mathrm{CH}_{2}\right] \mathrm{PP}$ (trace 1), trace 1 incubated with wt-MoaC (trace 2), and trace 1 incubated with K131A-MoaC (trace 3), detected by UVvis absorption (A, 254 and $\mathbf{B}, 330 \mathrm{~nm})$ and by extracted ion (C, $m / z=442.0523 \pm 0.050)$ chromatography. (D) Mass spectra at retention time of $1.8 \mathrm{~min}$ in $\mathbf{C}$. The signals unique to the reaction without MoaC were highlighted in bold red $\left(\mathrm{m} / \mathrm{z}=442.052\right.$ and 464.036), which agreed with the mass of $\left.3^{\prime}, 8-\mathrm{cH}_{2} \mathrm{GMP}_{\mathrm{CH}}\right] \mathrm{P}$. 
A.<smiles>[R]Nc1nc(N)[nH]c(=O)c1N[R]</smiles>

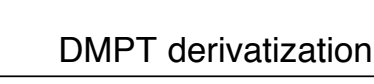

1) $\mathrm{pH} 2.0$, Heat

2) 2,3-Butanedione, $\mathrm{pH} 8.5$

3) Heat

Acid-labile triaminopyrimidinone (Intermediate $\mathrm{X}$ )<smiles>[R]C1Nc2nc(N)[nH]c(=O)c2NC1[R]</smiles>

cPMP and other pterins<smiles>Cc1nc2nc(N)[nH]c(=O)c2nc1C</smiles>

Dimethylpterin (DMPT)

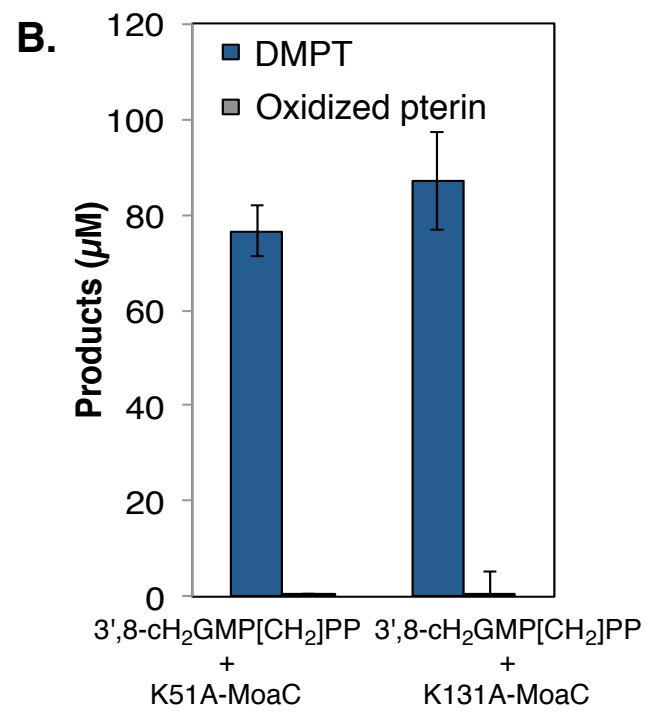

Figure S2. Chemical characterization of $[(\mathbf{a}, \boldsymbol{\beta})$-methyleno]intermediate $\mathbf{X}$. (A) Scheme for the derivatization of triaminopyrimidine and pterin into their fluorescent derivatives, dimethylpterin (DMPT), and oxidized pterin, respectively. (B) Results of the chemical derivatization of products of the assays of K51A- and $\mathrm{K} 131 \mathrm{~A}-\mathrm{MoaC}$ with $3^{\prime}, 8-\mathrm{CH}_{2} \mathrm{GMP}\left[\mathrm{CH}_{2}\right] \mathrm{PP}$ as substrate. The assays were performed as described in the legend of Figure 2A. The products were treated with TCA followed by with butane-2,3-dione for the detection of molecules with acid-labile triaminopyrimidinone (blue bars), or with $\mathrm{KI} / \mathrm{I}_{2}$ at $\mathrm{pH} 2.0$ to detect pterin molecules (gray bars). Error bars represent standard derivation from replicates of anaerobic HPLC with K51A- and $\mathrm{K} 131 \mathrm{~A}-\mathrm{MoaC}$ reactions with GMP[CH $\left.\mathrm{CH}_{2}\right] \mathrm{PP}$. The products from the reactions with $\mathrm{K} 51 \mathrm{~A}-$ and $\mathrm{K} 131 \mathrm{~A}-\mathrm{MoaC}$ were quantitatively converted to DMPT, while no detectable level of pterin was observed. These observations are consistent with the previous observation for intermediate $X,{ }^{1}$ and support the formation of $[(\alpha, \beta)$ methyleno]intermediate $\mathrm{X}$. 
A. UV absorption chromatography $(350 \mathrm{~nm})$

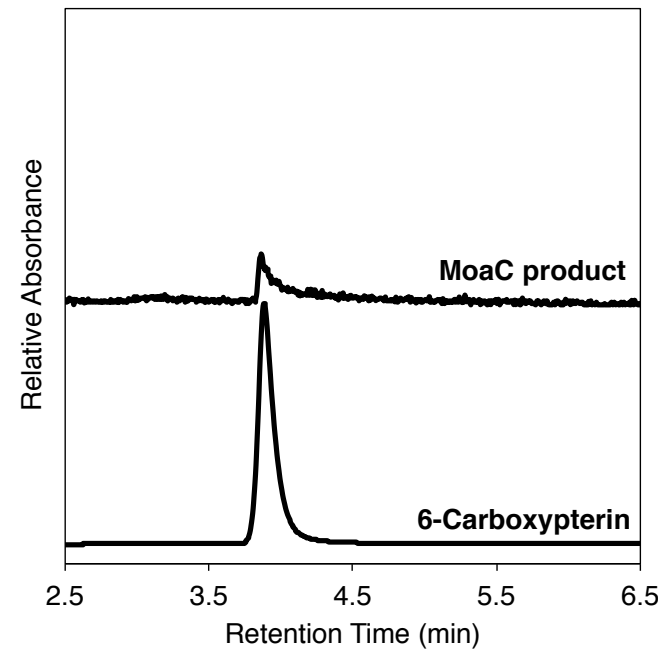

C. Mass spectra at $3.8 \mathrm{~min}$

MoaC product

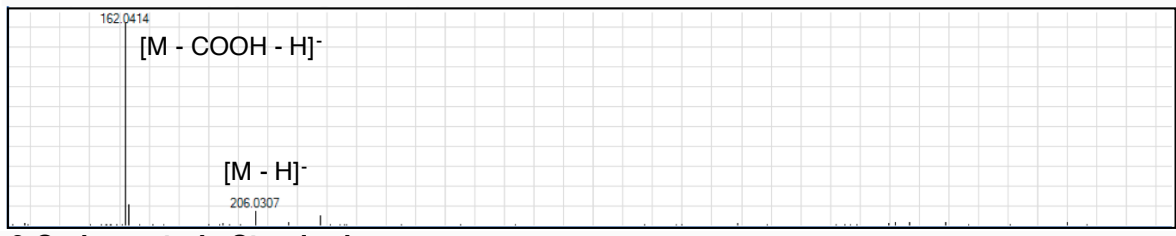

6-Carboxypterin Standard

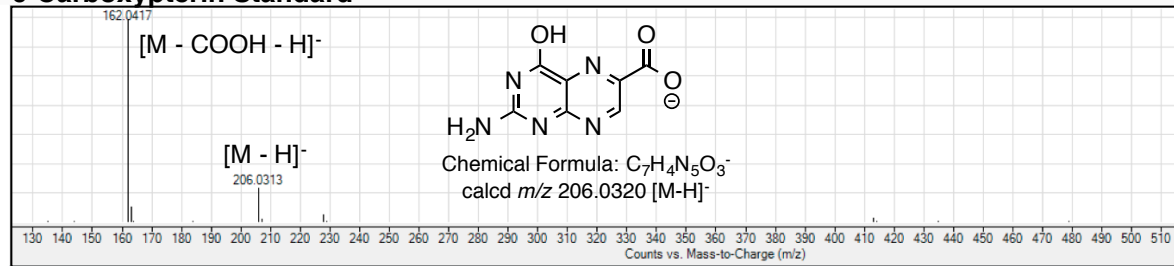

B. Extracted ion chromatography $(\mathrm{m} / \mathrm{z} 206.032 \pm 0.050)$

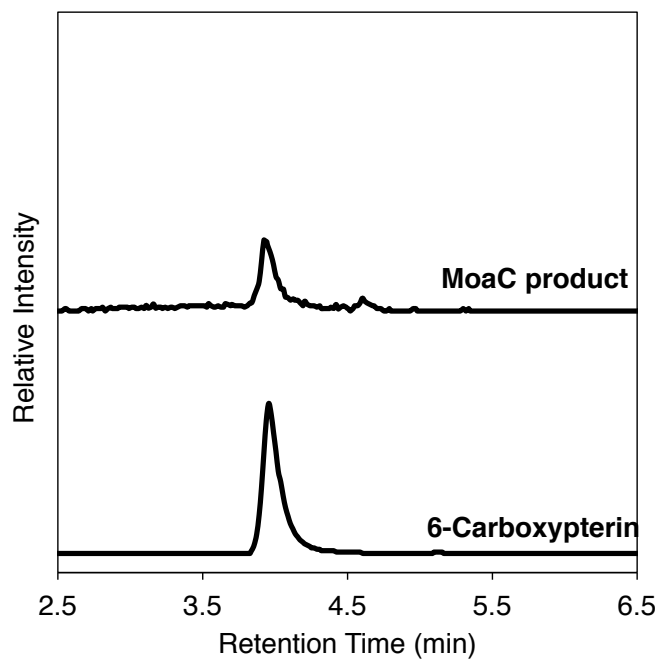

Figure S3. LCMS characterization of a stable derivative of the small molecule released from the wtMoaC assay with $3^{\prime}, 8-\mathbf{c H}_{2} \mathrm{GMP}\left[\mathrm{CH}_{2}\right] \mathrm{PP}$. (A,B) Liquid chromatography analysis of the small molecule identified in the wt-MoaC assay with $3^{\prime}, 8-\mathrm{CH}_{2} \mathrm{GMP}\left[\mathrm{CH}_{2}\right] \mathrm{PP}$ assay detected by UV-vis absorption at $350 \mathrm{~nm}(\mathbf{A}$, top trace) or by mass intensity at $\mathrm{m} / \mathrm{z} 206.032 \pm 0.050$ (B, top trace). Analyses for the derivative of the MoaC product and an authentic 6-carboxypterin are shown (bottom traces). The derivative of MoaC product was purified by HPLC (Figure 6A). (C) ESI-TOF mass spectra of elution at $3.8 \mathrm{~min}$ of $\mathbf{B}$. Analyses for the derivative of MoaC product and authentic 6-carboxypterin are shown. 

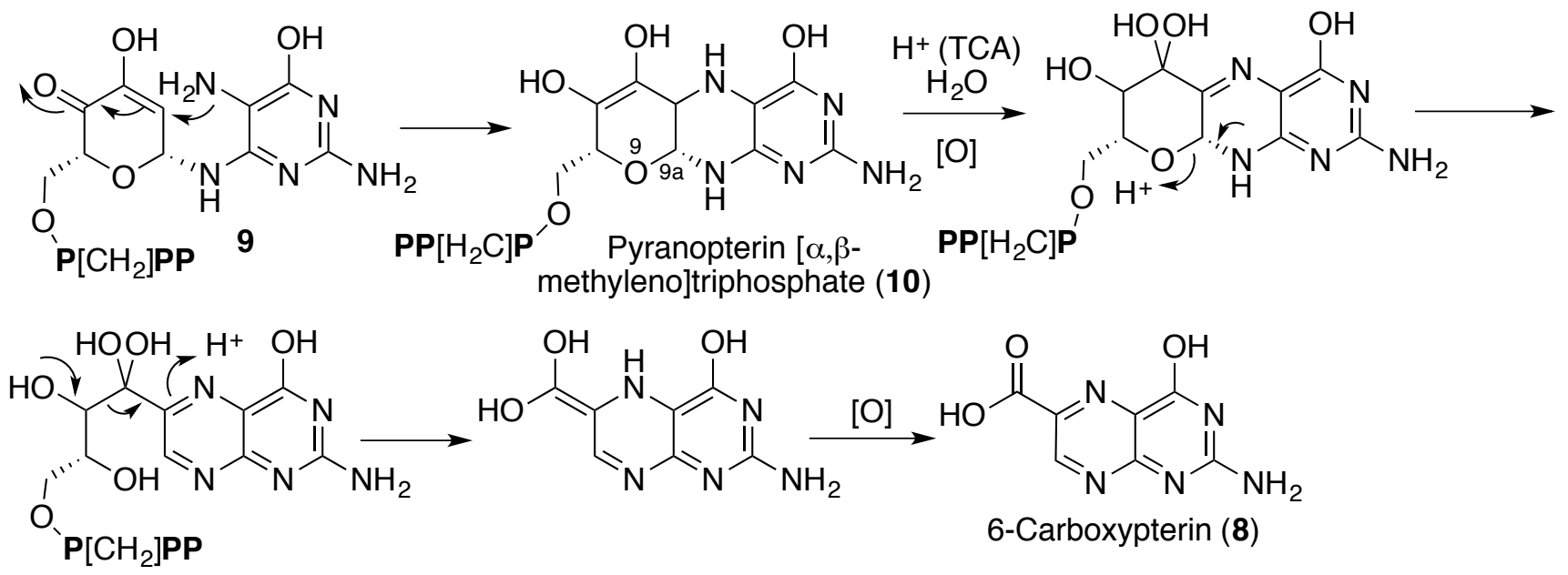

Figure S4. Possible mechanism of non-enzymatic conversion of 9 into 6-carboxypterin.

6-Carboxypterin (8) is likely a product of spontaneous decomposition of compound $\mathbf{9}$, the proposed product of wt-MoaC reaction with 3',8- $\mathrm{CH}_{2} \mathrm{GMP}\left[\mathrm{CH}_{2}\right] \mathrm{PP}$. The transformation is initiated by the conversion of compound 9 into 10 after the release of $\mathbf{9}$ from the MoaC active site. The mechanism of the conversion of 10 into $\mathbf{8}$ is based on precedents in related pyranopterin compounds. ${ }^{2,3}$ 


\section{References}

(1) Hover, B. M.; Tonthat, N. K.; Schumacher, M. A.; Yokoyama, K. Proc Natl Acad Sci U S A 2015, 112, 6347-6352.

(2) Johnson, J. L.; Hainline, B. E.; Rajagopalan, K. V.; Arison, B. H. J Biol Chem 1984, 259, 5414-5422.

(3) Mathis, J. B.; Brown, G. M. J Biol Chem 1970, 245, 3015-3025. 